\title{
Outcome of pulmonary rehabilitation in patients with stable chronic obstructive pulmonary disease at Chest Department, Zagazig University Hospitals (2014-2016)
} Samah M. Shehata, Monzer M. Refky, Maha M. Al gabry, Ramadan M. Nafae

Context Chronic obstructive pulmonary disease (COPD) is a very disabling disorder that is accompanied by some extrapulmonary manifestations. Pulmonary rehabilitation (PR) is outlined to enhance both physical and psychological condition of patients with chronic chest diseases.

Aims We aimed at evaluating the effectiveness of 8 weeks of outpatient PR on improving breathlessness, quality of life, exercise tolerance, and functional ability in patients with stable COPD.

Settings and design A randomized controlled clinical study was conducted.

Patients and methods The current study was carried out on 80 patients with stable COPD who were classified into group 1 , where 40 patients were subjected to usual pharmacological therapy for COPD and PR for 8 weeks, and group 2, where 40 patients were subjected to usual pharmacological therapy only. Both groups were assessed regarding spirometric pulmonary function, arterial blood gases, 6 min walk test, dyspnea score (modified-Medical Research Council), and health-related quality of life [Saint George respiratory questionnaire (SGRQ)]. SPSS 20.0 for windows and MedCalc 13 for windows were used for statistical analysis.

Results Approximately $50 \%$ of patients in group 1 showed improvement in dyspnea, whereas only $25 \%$ of patients were improved in group 2. Moreover, there was a statistical significance difference between both patient groups

\section{Introduction}

Chronic obstructive pulmonary disease (COPD) is the most common chronic lung disease, which is largely attributed to lung-related death and disability. COPD is a very disabling disorder that is accompanied by some extrapulmonary manifestations, but it can be prevented and treated [1].

The breathlessness developed at rest and/or during daily living activities in patients with COPD can cause an increasingly sedentary lifestyle, a progressive worsening in functional capacity, and may cause home isolation. With progressive inactivity, cardiovascular function and skeletal muscle mass decrease. The deterioration in aerobic fitness and strength creates a vicious cycle that leads to more exertional dyspnea, muscular fatigue, an evitable loss of functional independence, and depression [2].

Pulmonary rehabilitation $(\mathrm{PR})$ is a comprehensive program that depends on a complete assessment of patients and subsequent patient-tailored therapies, regarding the post-treatment improvement in 6 min walk distance (6MWD) and the post-treatment improvement in the three components of SGRQ score and also in the total SGRQ score $(P<0.001)$. The improvement in 6MWD showed significantly inverse correlation with the baseline age, modified-Medical Research Council, and SGRQ scores, whereas the improvement in 6MWD was significantly directly correlated with the baseline forced expiratory volume in $1 \mathrm{~s}$, forced expiratory volume in $1 \mathrm{~s} /$ forced vital capacity, $\mathrm{PaO}_{2}$, and baseline 6MWD.

Conclusion PR for patients with stable COPD is an effective tool for improving quality of life, exercise capacity, and dyspnea score.

Egypt J Bronchol 2018 12:279-287

( 2018 Egyptian Journal of Bronchology

Egyptian Journal of Bronchology 2018 12:279-287

Keywords: chronic obstructive pulmonary disease, exercise training, outcomes, pulmonary rehabilitation

Chest Department, Zagazig University and Chest Hospital, Ministry of Health, Zagazig, Egypt

Correspondence to Samah M. Shehata, MD, Chest Department, Zagazig University, Zagazig, 44519, Egypt. Tel: +20 106317 5135; e-mail: sama7she7ata2000@yahoo.com

Received 14 March 2018 Accepted 7 June 2018

which consist of patient education and exercise training, outlined to enhance both physical and psychological condition of patients with chronic chest diseases and to encourage the long-term adherence to health-enhancing behaviors [3].

We aimed at evaluating the effectiveness of 8 weeks of outpatient PR on improving breathlessness, quality of life, exercise tolerance, and functional ability in patients with stable COPD.

\section{Patients and methods}

This randomized controlled clinical study was carried out on 80 patients with stable COPD of either sex with age ranges from 45 to 75 years at Chest Department, Zagazig University Hospitals, in the period between

This is an open access journal, and articles are distributed under the terms of the Creative Commons Attribution-NonCommercial-ShareAlike 4.0 License, which allows others to remix, tweak, and build upon the work non-commercially, as long as appropriate credit is given and the new creations are licensed under the identical terms. 
December 2014 and June 2016, after the approval from Institutional Review Board Committee, Zagazig University (IRB. $\mathrm{Zu}$ ).

\section{Inclusion criteria}

The following were the inclusion criteria:

(1) Cooperating patients with COPD.

(2) Presenting with a postbronchodilator $30 \% \leq$ FEV1\% predicted $<80 \%$ (moderate and severe airflow limitation only).

(3) Free from exacerbations 4 weeks before starting PR.

\section{Exclusion criteria}

(1) Heart failure and unstable angina or recent ( $<6$ months) myocardial infarction.

(2) Prior cardiac or pulmonary surgery.

(3) Patient was on long-term oxygen therapy or received systemic steroid during the past 4 weeks.

(4) Presence of neuromuscular and orthopedic diseases.

(5) Uncontrolled disabling diseases, for example, diabetes, hypertension, and renal or hepatic diseases.

(6) Patient was not interested in the program.

(7) Patient did not complete $85 \%$ of PR.

The patients were classified into two groups (test and control group) after taking an informed consent from them:

(1) Group 1 (test group): 40 patients were subjected to usual pharmacological therapy for COPD added to it PR (exercise training, health education) which was conducted for 8 weeks.

(2) Group 2 (control group): 40 patients were subjected to usual pharmacological therapy only for COPD.

All patients in the study were subjected to the following:

(1) Clinical diagnosis depending on medical history, especially smoking and progressive dyspnea, with irreversible airflow obstruction on spirometry, complete physical examination, and chest radiography examination [4].

(2) ECG for all patients, and ECHO when indicated to evaluate the cardiac condition.

(3) Degree of dyspnea related to activities was assessed by modified-Medical Research Council (mMRC) [5].
(4) Spirometric pulmonary function test was performed by using computerized pulmonary function apparatus (1999, ZAN 100 spirometer; ZAN Messgeraete GmbH Company, Germany) including prebronchodilator/postbronchodilator forced expiratory volume in $1 \mathrm{~s}\left(\mathrm{FEV}_{1}\right)$, forced vital capacity (FVC), and $\mathrm{FEV}_{1} / \mathrm{FVC}$ to diagnose and assess degree of airway obstruction.

(5) Arterial blood gases (ABGs).

(6) Quality-of-life assessment by Saint George respiratory questionnaire (SGRQ), which is a disease-specific questionnaire validated for measuring impaired health in patients with respiratory disorders; scores range from 100, representing worst possible health status, to 0 , best possible. It consisted of two parts: part 1 (the symptom score) covers the patients' symptoms that occurred in the preceding period from 1 month to 1 year, and part 2 addresses the patients' current state (i.e. how they are these days), which consists of the activity score (measures the disturbances in patient's daily activity) and the impact score (measures the disturbances in patient's psychosocial condition) [6].

(7) Six-min walk test (6MWT): this test estimates the distance walked quickly by a patient on a hard and flat surface for $6 \mathrm{~min}$ [the $6 \mathrm{~min}$ walk distance (6MWD)] [7].

\section{Methods (pulmonary rehabilitation)}

Patient health education [4]

It should help patients to acquire the following:

(1) Basic information about COPD, risk factors, recognition of symptoms, and management.

(2) Knowledge about the value of physical exercise for patients with COPD and the appropriate types of exercise.

(3) Understanding the correct and proper use of medications.

(4) Advice about when to seek help and decision making during exacerbations.

\section{Exercise training programs [8]}

Different modes of training were used for both upper and lower limbs. They included endurance (aerobic), strengthening (resistance) exercises, and breathing retraining technique.

(1) Endurance training:

(a) Cycle based using ergometer.

(b) Walking based using treadmill.

(c) Arm exercise using arm wheel.

(2) Strengthening training (resistance training): 

(a) Free weights.
(b) TheraBand.
(c) Ball exercise.

(3) Breathing retraining (or breathing exercises). Breathing retraining is a simple approach aiming to enhance respiratory muscle recruitment to reduce dyspnea and improve respiratory muscle performance. They included the following:

(a) Pursed-lip breathing in which the patient inhales through the nose with mouth closed and exhales through mouth lips pursed tightly, provided that the exhalation was twice as long as the inhalation.

(b) Diaphragmatic breathing in which the patient inhales slowly through the nose with the abdomen expanded outward and exhales slowly through pursed lip while drawing the abdomen inward.

\section{Physical exercise schedule during the study}

(1) Warming up phase: this included stretching, range of motion, and starting activities at low intensity level.

(2) Physical exercise included the following:

(a) Breathing retraining in the form of pursed-lip breathing and diaphragmatic breathing.

(b) Exercise training regarding frequency, intensity, time, and type (FITT) are shown in Table 1.

The exercise training was tailored and selected to the patients depending on their ability to withstand the exercise and their disease severity.
(3) Cool down phase: this allows the body to gradually recover from the training phase. Heart rate will return to near-resting values. Best cool down was to decrease the exercise intensity and to perform some stretching activities in the warm up.

At the end of 8 weeks, both groups were subjected to the following:

(1) Subjective methods including the following:

(a) Assessment of SGRQ questionnaire.

(b) Assessment of dyspnea by mMRC.

(2) Objective methods including the following:
(a) 6MWT
(b) Spirometry.
(c) ABG.

\section{Statistical analysis}

All data were collected, tabulated, and statistically analyzed using SPSS 20.0 for windows (SPSS Inc., Chicago, Illinois, USA) and MedCalc 13 for windows (MedCalc Software bvba, Ostend, Belgium). Quantitative data were expressed as the mean $\pm \mathrm{SD}$ and qualitative data were expressed as absolute frequencies (number) and relative frequencies (percentage).

Continuous data were checked for normality by using Shapiro-Wilk test. Independent Student's $t$-test was used to compare two groups of normally distributed data whereas Mann-Whitney $U$ was used for nonnormally distributed data. Percentages of categorical variables were compared using $\chi^{2}$-test or Fisher's exact test when appropriate. Spearman's rank correlation coefficient was calculated to assess relationship

Table 1 Exercise training program [8]

\begin{tabular}{|c|c|c|c|}
\hline & $\begin{array}{l}\text { Continuous endurance } \\
\text { exercise }\end{array}$ & Interval endurance exercise ${ }^{a}$ & Strengthening exercise \\
\hline Frequency & 3 times/week & 3 times/week & 3 times/week \\
\hline \multirow[t]{2}{*}{ Intensity } & $\begin{array}{l}65 \% \text { of maximum heart rate } \\
\qquad\left(\mathrm{HR}_{\max }\right)^{\mathrm{b}}\end{array}$ & $75 \%$ of $\mathrm{HR}_{\max }$ & $\begin{array}{l}\text { Targeting local muscle exhaustion within 6-12 } \\
\text { repetitions }\end{array}$ \\
\hline & $\uparrow$ by 5 to reach $85 \%$ of $\mathrm{HR}_{\max }$ & $\uparrow$ by $5 \%$ to reach $100 \%$ of $\mathrm{HR}_{\max }$ & $\begin{array}{l}\text { Overload, if patient can do same repetitions for } \\
\qquad 2 \text { sessions }{ }^{c}\end{array}$ \\
\hline \multirow[t]{2}{*}{ Type (mode) } & Continuous & $30 \mathrm{~s}$ exercise, $30 \mathrm{~s}$ rest & \\
\hline & & 20 s exercise, 40 s rest & \\
\hline \multirow{2}{*}{$\begin{array}{l}\text { Time } \\
\text { (duration) }\end{array}$} & Started by $10-15 \min$ & Started by $15-20 \mathrm{~min}$ & $2-4$ sets of $6-12$ repetitions \\
\hline & $\uparrow$ progressively to $30 \mathrm{~min}$ & $\begin{array}{l}\uparrow \text { progressively to } 45 \mathrm{~min} \text { (including } \\
\text { resting time) }\end{array}$ & \\
\hline \multirow{3}{*}{$\begin{array}{l}\text { End of } \\
\text { exercise }\end{array}$} & Modified Borg scale >4-6 & Modified Borg scale $>4-6$ & Muscle fatigue \\
\hline & $\begin{array}{l}\text { Maximum heart rate is } \\
\text { reached }\end{array}$ & Peak heart rate is reached & Modified Borg scale $>4-6$ \\
\hline & $\mathrm{SaO}_{2}<88 \%{ }^{\mathrm{d}}$ & $\mathrm{SaO}_{2}<88 \% \%^{\mathrm{d}}$ & \\
\hline
\end{tabular}

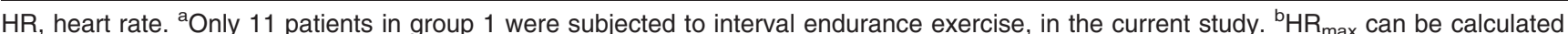
from this equation (220 minus age of the patient). ' Overload can be achieved by increase resistance or weight, increasing repetitions/set,

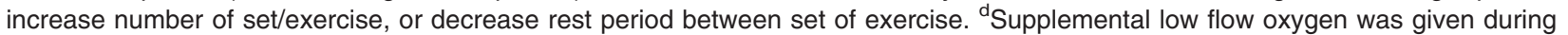
exercise if desaturation occurred. 
between $\triangle$ SGRQ (Total), $\Delta 6 \mathrm{MWT}$, and baseline study parameters, where values near to 1 were indicator of strong relationship and values near 0 were indicator of weak relationship.

\section{Results}

Both patients groups were matched regarding age, sex, smoking habit, and associated comorbidities. The mean age was $54 \pm 4.85$ and $54.72 \pm 5.31$ years in group 1 and group 2, respectively. In group 1 and group 2 , male patients represented 87.5 and $82.5 \%$, respectively (data not shown).

There was no statistical significance difference between both patient groups regarding pretreatment mean mMRC, spirometric parameters, ABG, SGRQ scores, and 6MWD (Tables 2-4).

Table 5 shows that $50 \%$ of patients in group 1 showed improvement in dyspnea, whereas only $25 \%$ of patients were improved in group 2, with statistically significant difference between both the groups. Moreover, there was a statistically significant difference between both patient groups regarding the post-treatment improvement in 6MWD.

Table 6 shows that there was no statistically significant difference between both patient groups regarding post-treatment change in spirometric parameters $\left(\mathrm{FEV}_{1}\right.$ or $\left.\mathrm{FEV}_{1} / \mathrm{FVC}\right)$. Moreover, there was no statistically significant difference between both patient groups regarding post-treatment improvement in $\mathrm{PaO}_{2}$ or $\mathrm{PaCO}_{2}$ (data not shown).

Figure 1 demonstrates a comparison between group 1 and group 2 regarding $\triangle 6 \mathrm{MWD}$, where the $6 \mathrm{MWD}$ increased greater than $54 \mathrm{~m}$ in $72.5 \%$ of patients in group 1 versus $7.5 \%$ in group $2(P<0.001)$.

Figure 2 illustrates that there was a statistically significant difference between both patient groups regarding the post-treatment improvement in the three components Of SGRQ score (symptoms, activity, and impact) and also the total SGRQ score $(P<0.001)$.

The improvement in SGRQ total score showed nonsignificant inverse correlation with the baseline age, mMRC, $\mathrm{PaCO}_{2}$, and SGRQ (symptoms, activity, impact, and total) scores and nonsignificant direct correlation with the baseline $\mathrm{FEV}_{1}, \mathrm{FEV}_{1} / \mathrm{FVC}$, $\mathrm{PaO}_{2}$, and 6MWD (data not shown).

Table 7 shows that there was a significant correlation between some baseline variables and the improvement in 6MWD.

Table 2 Comparison between group 1 and group 2 regarding pretreatment modified-Medical Research Council and 6 min walk distance

\begin{tabular}{lccrr}
\hline & Group 1 $(N=40)(m e a n \pm S D)$ & Group 2 $(N=40)($ mean $\pm S D)$ & $t$ & $P$ \\
\hline mMRC & $2.95 \pm 0.67$ & $2.95 \pm 0.59$ & $-0.022^{*}$ & 0.982 (NS) \\
6MWD $(m)$ & $419.52 \pm 63.64$ & $419.75 \pm 63.25$ & $-0.019^{*}$ & 0.985 (NS) \\
\hline
\end{tabular}

6MWD, 6 min walk distance; mMRC, modified-Medical Research Council. ${ }^{*}$ Mann-Whitney U-test.

Table 3 Comparison between group 1 and group 2 regarding pretreatment spirometric function tests

\begin{tabular}{lcccr}
\hline & Group 1 $(N=40)$ & Group 2 $(N=40)$ & $t$ & $P$ \\
\hline FEV $\%$ predicted & & & & 0.500 (NS) \\
Mean \pm SD & $60.35 \pm 12.69$ & $59.12 \pm 12.24$ & $-0.674^{*}$ & 0.556 (NS) \\
$<50 \%[n(\%)]$ & $8(20)$ & $6(15)$ & $0.346^{\dagger}$ & \\
$\geq 50 \%[n(\%)]$ & $32(80)$ & $34(85)$ & & $0.425^{\ddagger}$ \\
FEV 1 FVC (mean \pm SD) & $60.80 \pm 7.71$ & $60.10 \pm 7.01$ & 0.672 (NS) \\
\hline
\end{tabular}

$\mathrm{FEV}_{1}$, forced expiratory volume in the first second; FVC, forced vital capacity. *Mann-Whitney $U$-test. ${ }^{\dagger} \chi^{2}$-test. ${ }^{\star}$ Independent samples Student's $t$-test.

Table 4 Comparison between group 1 and group 2 regarding pretreatment health status evaluation measured by Saint George respiratory questionnaire

\begin{tabular}{|c|c|c|c|c|}
\hline & $\begin{array}{c}\text { Group } 1 \\
(N=40)(\text { mean } \pm S D)\end{array}$ & Group $2(N=40)($ mean $\pm S D)$ & $t$ & $P$ \\
\hline SGRQ (symptoms) & $46.75 \pm 11.68$ & $46.15 \pm 11.84$ & $0.228^{*}$ & $0.820(\mathrm{NS})$ \\
\hline SGRQ (activity) & $49.62 \pm 10.52$ & $49.77 \pm 10.41$ & $-0.064^{*}$ & 0.949 (NS) \\
\hline SGRQ (impact) & $29.87 \pm 11.13$ & $28.90 \pm 11.26$ & $0.389^{*}$ & 0.698 (NS) \\
\hline SGRQ (total) & $38.32 \pm 9.08$ & $38.27 \pm 9.48$ & $0.024^{*}$ & 0.981 (NS) \\
\hline
\end{tabular}

SGRQ, Saint George respiratory questionnaire. *Independent samples Student's $t$-test. 
Table 5 Comparison between group 1 and group 2 regarding post-treatment change in modified-Medical Research Council and 6 min walk distance

\begin{tabular}{|c|c|c|c|c|}
\hline & Group $1(N=40)$ & Group $2(N=40)$ & $t$ & $P$ \\
\hline$\Delta \mathrm{mMRC}(\operatorname{mean} \pm \mathrm{SD})$ & $-0.50 \pm 0.50$ & $-0.25 \pm 0.43$ & $-2.295^{\star}$ & $0.022(\mathrm{~S})$ \\
\hline No change $[n(\%)]$ & $20(50)$ & $30(75)$ & $5.333^{\dagger}$ & $0.021(\mathrm{~S})$ \\
\hline $\begin{array}{l}\text { Decrease } \\
{[n(\%)]}\end{array}$ & $20(50)$ & $10(25)$ & & \\
\hline$\Delta 6 \mathrm{MWD}(\operatorname{mean} \pm \mathrm{SD})(\mathrm{m})$ & $54.87 \pm 31.06$ & $36.62 \pm 23.49$ & $-5.189^{\star}$ & $<0.001(\mathrm{HS})$ \\
\hline
\end{tabular}

6MWD, 6 min walk distance; mMRC, modified-Medical Research Council; S, significant. *Mann-Whitney U-test. ${ }^{\dagger} \chi^{2}$-test.

Table 6 Comparison between group 1 and group 2 regarding post-treatment change in spirometric parameters

\begin{tabular}{lccc}
\hline & $\begin{array}{c}\text { Group 1 } \\
(N=40) \\
(\text { mean } \pm \text { SD })\end{array}$ & $\begin{array}{c}\text { Group 2 }(N=40) \text { (mean } \\
\pm S D)\end{array}$ & $P$ \\
\hline $\begin{array}{l}\Delta \mathrm{FEV}_{1} \\
(\mathrm{ml})\end{array}$ & $167 \pm 0.76$ & $102 \pm 0.73$ & $\begin{array}{c}<0.351 \\
(\mathrm{NS})\end{array}$ \\
$\begin{array}{l}\Delta \mathrm{FEV} \\
\mathrm{FVC}\end{array}$ & $1.70 \pm 0.67$ & $1.05 \pm 0.78$ & $\begin{array}{c}<0.672 \\
(\mathrm{NS})\end{array}$ \\
\hline
\end{tabular}

$\mathrm{FEV}_{1}$, forced expiratory volume in $1 \mathrm{~s} ; \mathrm{FVC}$, forced vital capacity.

Figure 1

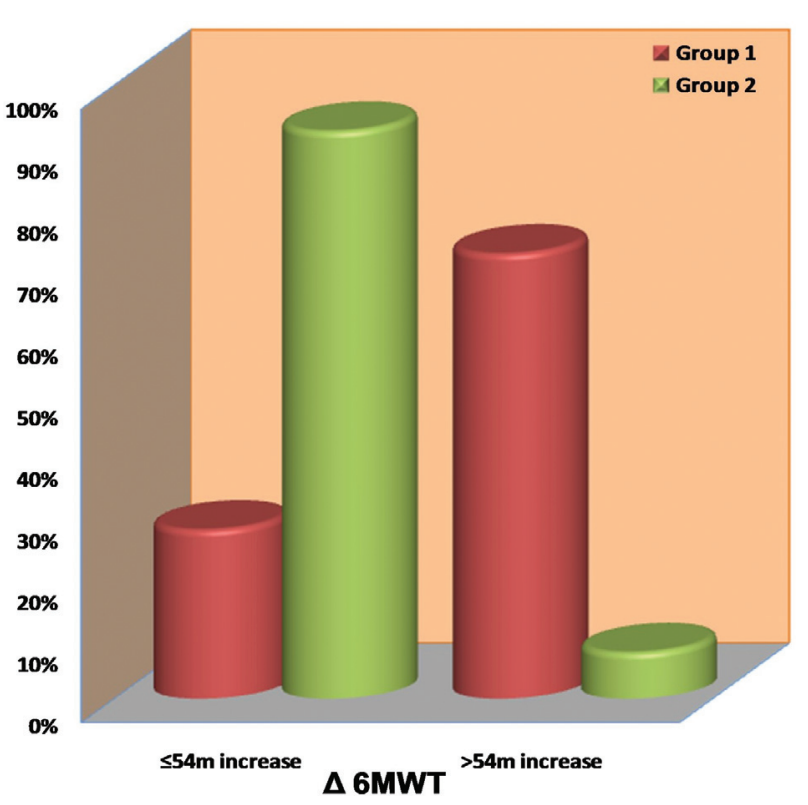

Bar chart shows comparison between group 1 and group 2 regarding $\triangle 6 \mathrm{MWD}$. 6MWD, 6 min walk distance.

\section{Discussion}

COPD is characterized by poorly reversible airflow limitation and dyspnea [9]. While the disease progresses, systemic manifestations develop in some patients, such as exercise limitation, peripheral muscle dysfunction [10], and frequent hospitalizations owing to recurrent exacerbations [11]. COPD is considered to have poor response to treatment as most therapies have minimal effect on the impaired lung function [12].
Figure 2

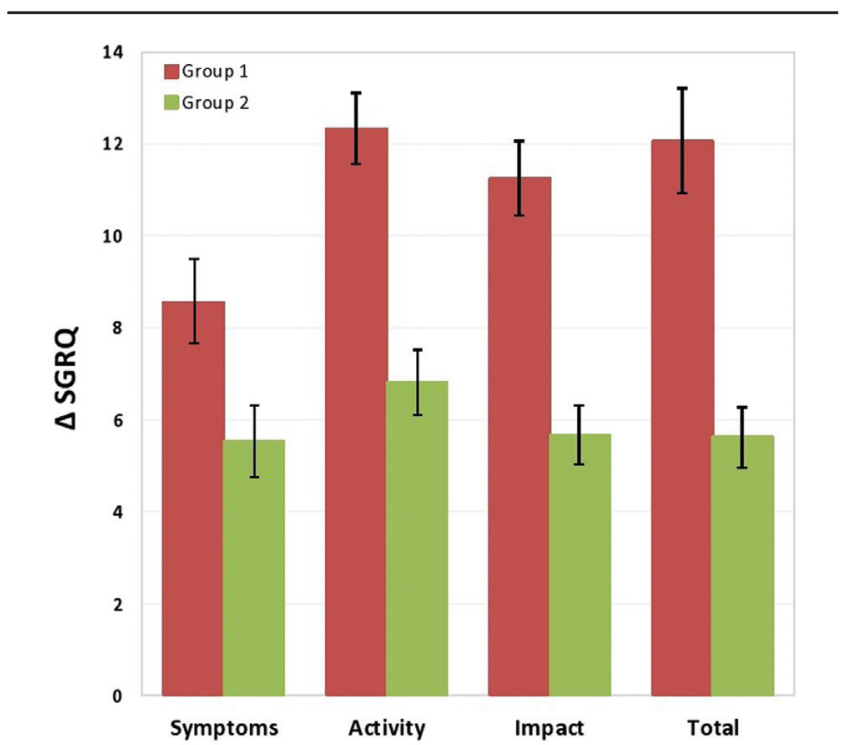

Error bar chart shows comparison between group 1 and group 2 regarding $\triangle S G R Q$; par represents mean and $Y$-error bar represents $95 \%$ confidence interval of mean. SGRQ, Saint George respiratory questionnaire.

PR is a treatment option that does not improve pulmonary function but has great effects on some disease consequences. PR decreases the burden of healthcare resource utilization [13], enhances health status [14], decreases dyspnea, and improves exercise capacity [15].

In the present study, we aimed at evaluating the effectiveness of 8 weeks of outpatient PR on improving breathlessness, quality of life, exercise tolerance, and functional ability in patients with stable COPD.

In this study, the pretreatment mean $\mathrm{FEV}_{1}$ and $\mathrm{FEV}_{1} /$ FVC were $60.35 \pm 12.69$ versus $59.12 \pm 12.24$ and 60.80 \pm 7.71 versus $60.10 \pm 7.01$ in both group 1 and group 2 , respectively. Rabe et al. [16] stated that PR should be applied for patients with COPD complaining of symptoms and having an $\mathrm{FEV}_{1}$ below $80 \%$.

Takigawa et al. [17] performed PR for patients with COPD with different severity stages and stated that all patients can benefit from $\mathrm{PR}$, irrespective of disease severity. Ergün et al. [18] also demonstrated that PR 


\begin{tabular}{l}
$\begin{array}{l}\text { Table } 7 \text { Correlation between baseline variables and change } \\
\text { (increase) in } 6 \text { min walk distance after pulmonary } \\
\text { rehabilitation }\end{array}$ \\
\cline { 2 - 3 } Variables \\
\cline { 2 - 3 }
\end{tabular}

$6 \mathrm{MWD}, 6$ min walk distance; $\mathrm{FEV}_{1}$, forced expiratory volume in $1 \mathrm{~s}$; FVC, forced vital capacity; mMRC, modified-Medical Research Council; $\mathrm{PaCO}_{2}$, partial arterial carbon dioxide tension; $\mathrm{PaO}_{2}$, partial arterial oxygen tension; $r$, Spearman's rank correlation coefficient; S, significant; SGRQ, Saint George respiratory questionnaire.

for patients with COPD was beneficial in severity stages (stages I and II) as well as in stages III and IV.

There was no statistical significance difference between both patient groups regarding pretreatment $\mathrm{ABG}$ parameters $\left(\mathrm{PaO}_{2}\right.$ and $\left.\mathrm{PaCO}_{2}\right)$ in the present study. Moreover, the mean $\mathrm{PaO}_{2}$ values were $70.50 \pm 4.84$ and $70.75 \pm 4.67$ in both test and control groups, respectively (data not shown). Gas exchange can predict the severity of COPD and may impair the daily living activity in patients with very severe COPD. Chronic hypoxic respiratory failure may lead to significant skeletal muscles abnormalities [19]. However, it is not a contraindication for PR, or for patients with hypercapnia [20].

In the current study, quality of life was assessed by SGRQ. In most studies, health-related quality of life (HRQOL) was assessed by applying either the chronic respiratory questionnaire (CRQ) or the SGRQ and the results of reliability, validity, and responsiveness did not significantly support one questionnaire over the other [21,22]. Moreover, Elçi et al. [23] assessed HRQOL using the SGRQ.

Cote and Celli [24] stated that as the goal of treatment of patients with COPD is mainly symptomatic improvement, the quality of life should be kept in mind as the primary outcome in PR.

The 6MWT measures the global and integrated responses of most body systems included during exercise such as the pulmonary and cardiovascular system, systemic and peripheral circulation, blood, and neuromuscular system. The 6MWT is a valuable parameter to evaluate exercise capacity in COPD [25].

Regarding the dyspnea improvement among the studied patients, the mean post-treatment decrease in dyspnea score (mMRC) was $-0.50 \pm 0.50$ in group 1 and $-0.25 \pm 0.43$ in group 2, with statistical significance difference when comparing both groups.

Lacasse et al. [26] concluded that rehabilitation improves dyspnea and fatigue, relieves emotional disturbances, and enhances exercise endurance.

Dyspnea and fatigue are the main complaints of patients with COPD, which were relieved by PR [27]. This improvement may be owing to an increase in the respiratory and skeletal muscle strength [28], breathing pattern adaptations, dyspnea desensitization [29], and subsequently decrease in dynamic hyperinflation [30].

The exercise capacity assessment in the present study showed that the 6MWD increase greater than $54 \mathrm{~m}$ in $72.5 \%$ of patients in group 1 versus $7.5 \%$ in group 2 and $6 \mathrm{MWD}$ increase less than or equal to $54 \mathrm{~m}$ in $27.5 \%$ in group 1 versus $92.5 \%$ in group 2. When comparing both groups, this increase was statistically highly significant $(P<0.001$; Fig. 1).

Karapolat et al. [31] and Borghi-Silva et al. [32] compared the difference in the mean change in 6MWT distance from baseline to follow-up between the PR and usual care (UC) groups, and there was a statistically significant improvement in functional exercise capacity for the $\mathrm{PR}$ group compared with the UC group $(P<0.05)$.

Moreover, Arnardóttir et al. [33] concluded that exercise capacity in patients with moderate to severe COPD was significantly improved by an 8-week training program, which consisted of two sessions a week, when intensive endurance training was involved in the program. The exercise response was not affected by disease severity, but this improvement was transient and exercise capacity declined again to baseline levels 6 months after training.

On the contrary, Carone et al. [34] found a nonsignificant improvement in the 6-min walk distance among both groups, of $48.2 \mathrm{~m}$ in the chronic respiratory failure (CRF) group and $47.8 \mathrm{~m}$ in the non-CRF group $(P>0.05)$. Close adherence to the rehabilitation program may be one of the causes of improvement noticed in both patient groups. 
Moreover, the improvement in patients with CRF denoted that exercise capacity can be alleviated also in patients with more severe COPD.

Troosters et al. [35] showed that rehabilitation programs with more frequent sessions are more effective than programs with less frequent sessions $(34.5 \mathrm{~m}$ with $<28$ sessions vs. $50.3 \mathrm{~m}$ with $>28$ sessions).

Improvement in 6MWD observed in the present study in group 1 may be attributed to the use of aerobic endurance and resistance/stretch exercise.

There was no statistical significance difference between both patient groups regarding either posttreatment change in spirometric parameters $\left(\mathrm{FEV}_{1}\right.$ or $\mathrm{FEV}_{1} / \mathrm{FVC}$ ), or post-treatment improvement in $\mathrm{PaO}_{2}$ or $\mathrm{PaCO}_{2}$, in the current study. This finding was in agreement with Arnardóttir et al. [33] who stated that after 8 weeks of training, spirometric function and $\mathrm{ABG}$ s were not affected by the period of training period in either group. Moreover, Lan et al. [36] found that there were no significant changes in $\mathrm{FEV}_{1}, \mathrm{FVC}$, and $\mathrm{FEV}_{1} / \mathrm{FVC}$ after 12 weeks of $\mathrm{PR}$.

On the contrary, Carone et al. [34] found that $\mathrm{FEV}_{1}$ slightly improved in the $\mathrm{CRF}$ group by approximately $112 \mathrm{ml}$ increase versus $154 \mathrm{ml}$ in the non-CRF group ( $P=0.03$ between groups, $P=0.001$ vs. baseline). This improvement may be owing to large cohort (1047 patients with COPD). Patients were subjected to a comprehensive $\mathrm{PR}$ program (patient education, exercise training, nutrition, and psychological support). Moreover, the exercise training program consisted of five supervised daily sessions per week.

HRQOL assessment in the current study showed that there was a statistically significant difference between both patient groups regarding the mean post-treatment improvement in the three components of SGRQ score (symptoms, activity, and impact) and also the total SGRQ score $(P<0.001)$. There was a statistically significant reduction ( $>4$ points) in the total SGRQ score immediately after completing the rehabilitation program, with $95 \%$ of patients in group 1 and $75 \%$ of patients in group $2(P=0.012)$.

Our results were in accordance with the studies by Engström et al. [37], Karapolat et al. [31], Elçi et al. [23], and Theander et al. [38] who compared the difference in the mean change in SGRQ scores from baseline to follow-up between the PR and UC groups. There was a statistically significant improvement in patient quality of life for the PR group compared with the UC group regarding the total score $(P<0.001)$ and activity scores $(P=0.02)$ of the SGRQ.

Moreover, Lan et al. [36] studied the SGRQ scores (total, symptoms, activity, and impact) before and after PR. They found that all domains of SGRQ were significantly improved (all $P<0.001$ ). The mean changes of scores were more that 4 units in all domains [39].

However, Arnardóttir et al. [33] stated that the SGRQ scores did not show significant improvement by exercise training in the studied groups, and this difference may be owing to the small number of studied patients in both groups, and also, two sessions a week for 8 weeks was an inadequate frequency for effective training.

In the current study, the improvement in 6MWD showed significantly inverse correlation with the baseline age, dyspnea measured by $\mathrm{mMRC}$, and health-related quality of life measured by SGRQ (symptoms, activity, impact, and total) scores, whereas the improvement in 6MWD was significantly directly correlated with the baseline $\mathrm{FEV}_{1}, \mathrm{FEV}_{1} / \mathrm{FVC}, \mathrm{PaO}_{2}$, and baseline 6MWD. However, there was a nonsignificant correlation between all the studied baseline variables and the improvement in SGRQ total score.

Vagaggini et al. [40] stated that the improvement in 6MWT was inversely correlated with the baseline 6MWD, meaning that patients with less exercise capacity had greater chance for improvement. Moreover, an improvement in 6MWT was directly correlated with $\mathrm{FEV}_{1} / \mathrm{FVC}$ but not with $\mathrm{FEV}_{1}$ or other spirometric parameters, so patients with less severe airway obstruction showed greater improvement in 6MWD.

Laviolette et al. [41] found that the baseline values of the 6MWD and of the SGRQ total scores were significantly correlated. The $6 \mathrm{MWT}$ was statistically associated with patient health status [42] and is a good predictor of mortality [43].

Garrod et al. [44] concluded that for changes in SGRQ score, a higher baseline 6MWD\% predicted was associated with greater improvement in SGRQ score (adjusted $r^{2}=0.13 ; P=0.03$ ), but this result is contrary to our result, where there is no significant correlation between change in SGRQ score and baseline 6MWD. 


\section{Conclusion}

(1) PR for patients with stable COPD is an effective tool for improving quality of life, exercise capacity, and dyspnea score.

(2) Some baseline clinical (age, dyspnea measured by mMRC, health-related quality of life measured by $\mathrm{SGRQ})$ and functional parameters $\left(\mathrm{FEV}_{1}, \mathrm{FEV}_{1} /\right.$ FVC, and $\mathrm{PaO}_{2}$ ) of patients with COPD are significantly correlated with the improvement in exercise capacity.

\section{Financial support and sponsorship}

Nil.

\section{Conflicts of interest}

There are no conflicts of interest.

\section{References}

1 Singer JP, Katz PP, Iribarren C, Omachi TA, Sanchez G, Yelin EH, etal. Both pulmonary and extra-pulmonary factors predict the development of disability in chronic obstructive pulmonary disease. Respiration 2013; 85:375-383.

2 Gosselink R, De Vos J, van den Heuvel SP, Segers J, Decramer M, Kwakkel G. Impact of inspiratory muscle training in patients with COPD: what is the evidence? Eur Respir J 2011; 37:416-425.

3 Spruit MA, Singh SJ, Garvey C, ZuWallack R, Nici L, Rochester C, et al. An official ATS/ERS statement: key concepts and advances in pulmonary rehabilitation. Am J Respir Crit Care Med 2013; 188:e13-e64.

4 Global Initiative for Chronic Obstructive pulmonary Disease (GOLD). Global strategy for the diagnosis, management, and prevention of COPD. 2014; Available at: http://www.goldcopd.org. [Last accessed 2014 Oct].

5 Mahler DA, Wells CK. Evaluation of clinical methods for rating dyspnea. Chest 1988; 93:580-586

6 Jones PW, Quirk FH, Baveystock CM. The St George's Respiratory Questionnaire. Respir Med 1991; 85(Suppl B):25-31. Discussion 33-37.

7 ATS Committee on Proficiency Standards for Clinical Pulmonary Function Laboratories. ATS statement: guidelines for the six-minute walk test. Am J Respir Crit Care Med 2002; 166:111-117.

8 Nici L, Donner C, Wouters E, Zuwallack R, Ambrosino N, Bourbeau J, et al. American Thoracic Society/ European Respiratory Society statement on pulmonary rehabilitation. Am J Respir Crit Care Med 2006; 173:1390-1413.

9 Celli BR, MacNee W. Standards for the diagnosis and treatment of patients with COPD: a summary of the ATS/ERS position paper. Eur Respir J 2004; 23:932-946

10 Gosselink R, Troosters T, Decramer M. Peripheral muscle weakness contributes to exercise limitation in COPD. Am J Respir Crit Care Med 1996; 153:976-980.

11 Connors AF Jr, Dawson NV, Thomas C, Harrell FE Jr, Desbiens N, Fulkerson WJ, et al. Outcomes following acute exacerbation of severe chronic obstructive lung disease. the SUPPORT investigators (Study to Understand Prognoses and Preferences for Outcomes and Risks of Treatments). Am J Respir Crit Care Med 1996; 154(Pt 1):959-967.

12 Anthonisen NR, Wright EC, Hodgkin JE. Prognosis in chronic obstructive pulmonary disease. Am Rev Respir Dis 1986; 133:14-20.

13 Bourbeau J, Julien M, Maltais F, Rouleau M, Beaupré A, Bégin R, et al. Reduction of hospital utilization in patients with chronic obstructive pulmonary disease: a disease-specific self-management intervention. Arch Intern Med 2003; 163:585-591.

14 Bowen JB, Votto JJ, Thrall RS, Haggerty MC, Stockdale-Woolley R, Bandyopadhyay $\mathrm{T}$, et al. Functional status following pulmonary rehabilitation. Chest 2000; 118:697-703.

15 Lacasse Y, Brosseau L, Milne S, Martin S, Wong E, Guyatt GH, et al. Pulmonary rehabilitation for chronic obstructive pulmonary disease. Cochrane Database Syst Rev 2002; 3:CD003793.

16 Rabe KF, Hurd S, Anzueto A, Barnes PJ, Buist SA, Calverley P, et al. Global strategy for the diagnosis, management, and prevention of chronic obstructive pulmonary disease: GOLD executive summary. Am J Respir Crit Care Med 2007; 176:532-555.

17 Takigawa N, Tada A, Soda R, Takahashi S, Kawata N, Shibayama T, et al. Comprehensive pulmonary rehabilitation according to severity of COPD. Respir Med 2007; 101:326-332.

18 Ergün P, Kaymaz D, Günay E, Erdogan Y, Turay UY, Demir N, et al. Comprehensive out-patient pulmonary rehabilitation: treatment outcomes in early and late stages of chronic obstructive pulmonary disease. Ann Thorac Med 2011; 6:70-76.

19 Sauleda J, García-Palmer F, Wiesner RJ, Tarraga S, Harting I, Tomás P, et al. Cytochrome oxidase activity and mitochondrial gene expression in skeletal muscle of patients with chronic obstructive pulmonary disease. Am $J$ Respir Crit Care Med 1998; 157(Pt 1):1413-1417.

20 Foster S, Lopez D, Thomas HM3rd. Pulmonary rehabilitation in COPD patients with elevated $\mathrm{CO}_{2}$. Am Rev Respir Dis 1988; 138:1519-1523.

21 Harper R, Brazier JE, Waterhouse JC, Walters SJ, Jones NM, Howard P. Comparison of outcome measures for patients with chronic obstructive pulmonary disease (COPD) in an outpatient setting. Thorax 1997; 52:879-887.

22 Rutten-van Mölken M, Roos B, Van Noord JA. An empirical comparison of the St George's respiratory questionnaire (SGRQ) and the chronic respiratory disease questionnaire (CRQ) in a clinical trial setting. Thorax 1999; 54:995-1003.

23 Elçi A, Börekçi S, Ovayolu N, Elbek O. The efficacy and applicability of a pulmonary rehabilitation programme for patients with COPD in a secondary-care community hospital. Respirology 2008; 13:703-707.

24 Cote CG, Celli BR. Pulmonary rehabilitation and the BODE index in COPD. Eur Respir J 2005; 26:630-636.

25 Casanova C, Cote CG, Marin JM, de Torres JP, Aguirre-Jaime A, Mendez $\mathrm{R}$, et al. The 6-min walking distance: long-term follow up in patients with COPD. Eur Respir J 2007; 29:535-540.

26 Lacasse Y, Goldstein R, Lasserson TJ, Martin S. Pulmonary rehabilitation for chronic obstructive pulmonary disease. Cochrane Database Syst Rev 2006; 18:CD003793.

27 Meek PM, Lareau SC. Critical outcomes in pulmonary rehabilitation: assessment and evaluation of dyspnea and fatigue. J Rehabil Res Dev 2003; 40(Suppl 2):13-24.

28 Sala E, Roca J, Marrades RM, Alonso J, Gonzalez De Suso JM, Moreno A, et al. Effects of endurance training on skeletal muscle bioenergetics in chronic obstructive pulmonary disease. Am J Respir Crit Care Med 1999; 159:1726-1734

29 Gigliotti F, Coli C, Bianchi R, Romagnoli I, Lanini B, Binazzi B, et al. Exercise training improves exertional dyspnea in patients with COPD: evidence of the role of mechanical factors. Chest 2003; 123: 1794-1802.

30 Casaburi R, Porszasz J, Burns MR, Carithers ER, Chang RS, Cooper CB. Physiologic benefits of exercise training in rehabilitation of patients with severe chronic obstructive pulmonary disease. Am J Respir Crit Care Med 1997; 155:1541-1551.

31 Karapolat H, Atasever A, Atamaz F, Kirazli Y, Elmas F, Erdinç E. Do the benefits gained using a short-term pulmonary rehabilitation program remain in COPD patients after participation? Lung 2007; 185:221-225

32 Borghi-Silva A, Arena R, Castello V, Simões RP, Martins LE, Catai AM, et al. Aerobic exercise training improves autonomic nervous control in patients with COPD. Respir Med 2009; 103:1503-1510.

33 Arnardóttir RH, Sörensen S, Ringqvist I, Larsson K. Two different training programmes for patients with COPD: a randomised study with 1-year follow-up. Respir Med 2006; 100:130-139.

34 Carone M, Patessio A, Ambrosino N, Baiardi P, Balbi B, Balzano G, et al. Efficacy of pulmonary rehabilitation in chronic respiratory failure (CRF) due to chronic obstructive pulmonary disease (COPD): The Maugeri Study. Respir Med 2007; 101:2447-2453.

35 Troosters T, Casaburi R, Gosselink R, Decramer M. Pulmonary rehabilitation in chronic obstructive pulmonary disease. Am $J$ Respir Crit Care Med 2005; 172:19-38.

36 Lan CC, Chu WH, Yang MC, Lee CH, Wu YK, Wu CP. Pulmonary rehabilitation in patients with COPD and normal exercise capacity. Respir Care 2013; 58:1482-1488.

37 Engström CP, Persson LO, Larsson S, Sullivan M. Health-related quality of life in COPD: why both disease-specific and generic measures should be used. Eur Respir J 2001; 18:69-76.

38 Theander K, Jakobsson P, Jörgensen N, Unosson M. Effects of pulmonary rehabilitation on fatigue, functional status and health perceptions in 
patients with chronic obstructive pulmonary disease: a randomized controlled trial. Clin Rehabil 2009; 23:125-136.

39 Jones PW. Interpreting thresholds for a clinically significant change in health status in asthma and COPD. Eur Respir $J$ 2002; 19:398-404.

40 Vagaggini B, Costa F, Antonelli S, de Simone C, de Cusatis G, Martino F, et al. Clinical predictors of the efficacy of a pulmonary rehabilitation programme in patients with COPD. Respir Med 2009; 103:1224-1230.

41 Laviolette L, Bourbeau J, Bernard S, Lacasse Y, Pepin V, Breton MJ, et al. Assessing the impact of pulmonary rehabilitation on functional status in COPD. Thorax 2008; 63:115-121.
42 Wijkstra PJ, TenVergert EM, van der Mark TW, Postma DS, van Altena R, Kraan $\mathrm{J}$, et al. Relation of lung function, maximal inspiratory pressure, dyspnoea, and quality of life with exercise capacity in patients with chronic obstructive pulmonary disease. Thorax 1994; 49:468-472.

43 Celli BR, Cote CG, Marin JM, Casanova C, Montes de Oca M, Mendez RA, et al. The body-mass index, airflow obstruction, dyspnea, and exercise capacity index in chronic obstructive pulmonary disease. $N$ Engl J Med 2004; 350:1005-1012.

44 Garrod R, Marshall J, Barley E, Jones PW. Predictors of success and failure in pulmonary rehabilitation. Eur Respir $J$ 2006; 27: 788-794. 